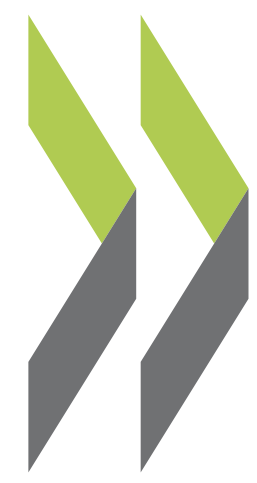

PEB Exchange, Programme on Educational Building 2003/15

\title{
An Industrial Building Converted into a Girls School in Australia
} Eamon Broderick 


\section{AN INDUSTRIAL BUILDING CONVERTED INTO A GIRLS SCHOOL IN AUSTRALIA}

An industrial building in Perth, Western Australia, has been converted into a secondary school to suit the particular needs of girls with educational and social difficulties. The aim of the building project was to provide a small school for approximately 30 students that caters to the needs of adolescent girls who are unable to operate within the mainstream or independent school systems.

The girls, aged 12 to 17 , are referred to the school for a variety of problems including chronic truancy; inability to function in a large classroom (because of poor literacy or social skills, lack of concentration, low achievement levels or disruptive behaviour); and drug-related and psychiatric problems. The students are in years eight to 12; however classes are grouped according to social development rather than age group. The classrooms accommodate small class sizes, typically six to eight students per teacher with a high degree of supervision and support for the students.

St. Clare's School was registered in 1957 and had operated over the years in many temporary locations around the city under the management of the Catholic
Education Centre of Western Australia. In 2001 two adjoining industrial workshops in a central city location were purchased in order to be converted into a permanent home for the school.

The school administration required the atmosphere of the school building to be homely and welcoming with light and bright spaces, more like a community centre than a typical classroom environment. A comfortable, safe and secure environment was essential.

\section{Courtyards}

The existing building was gloomy, with daylight entering only from high level windows in the "sawtooth" profile roof - a typical industrial shed. In addition the plan was very deep and did not allow for natural ventilation of the building once the space was subdivided into classrooms.

The architects' response was to cut three courtyards into the building - each with its own character and purpose. These courtyards bring sunlight and fresh air deep into the building and allow all rooms to have an external outlook. (This is unusual in Australia where schools are typically a campus design with freestanding buildings linked by open air covered walkways.)

Of the three courtyards, the "active" courtyard is the largest and almost fully paved; it is used for ball sports such as basketball and volleyball.

A second courtyard, the "quiet" courtyard, is heavily landscaped and offers a peaceful setting for reading or

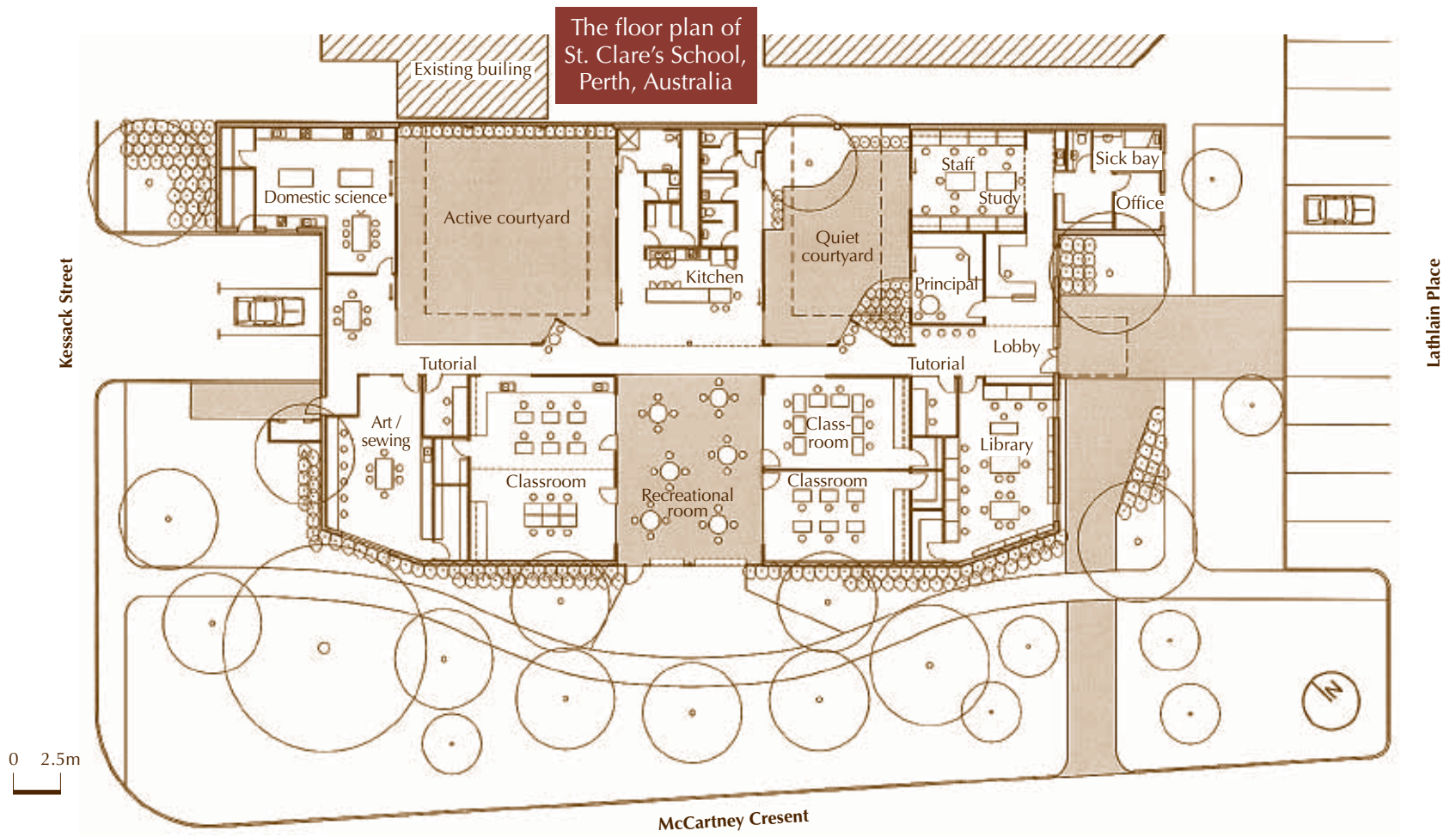


meditation. It is also the nearest to the staff office to allow close supervision of students.

The third courtyard, the "recreation room", is an internal space but is open to the elements. It has a translucent roof, a brick paved floor and large perforated steel shutters that can be opened to the landscaped garden outside the schools walls.

\section{The recreation room, a multi-use area}

The recreation room is the heart of the school and is intended for multiple uses, as an assembly area, a social café and an informal meeting place; located directly outside the core classrooms, it encourages impromptu encounters and discussions. The school principal, Sister Geraldine Mitchell has described this area as an "embracing" space that brings students together as a group.

It is here that meals are served and students interact with staff and each other. The recreation room has a café kitchen at one end and is open to the garden at the other. The space has been designed to feel more like an adult-oriented café than a typical school canteen - a task made easier by the small number of students involved. Morning tea, lunch and occasionally breakfast are provided here by the school, as well as tea and coffee at break times; breaks are short to reduce the risk of harmful interactions between students.

Furniture has been selected to be used in dining table configurations or drawn together to accommodate large groups.

As it is an "intermediate" (indoor/outdoor) space, the room has proven to be uncomfortably cold in winter, although the cool breeze is necessary in summer. Translucent blinds will be fitted to the openings to rectify this.

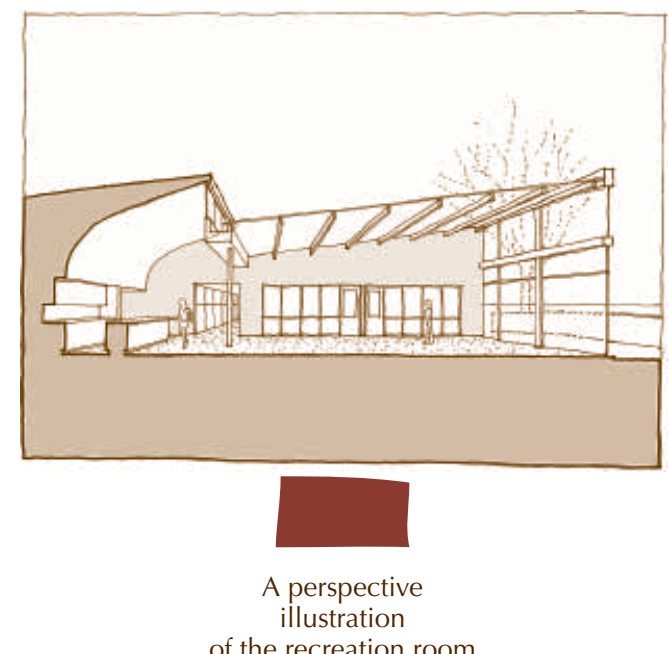

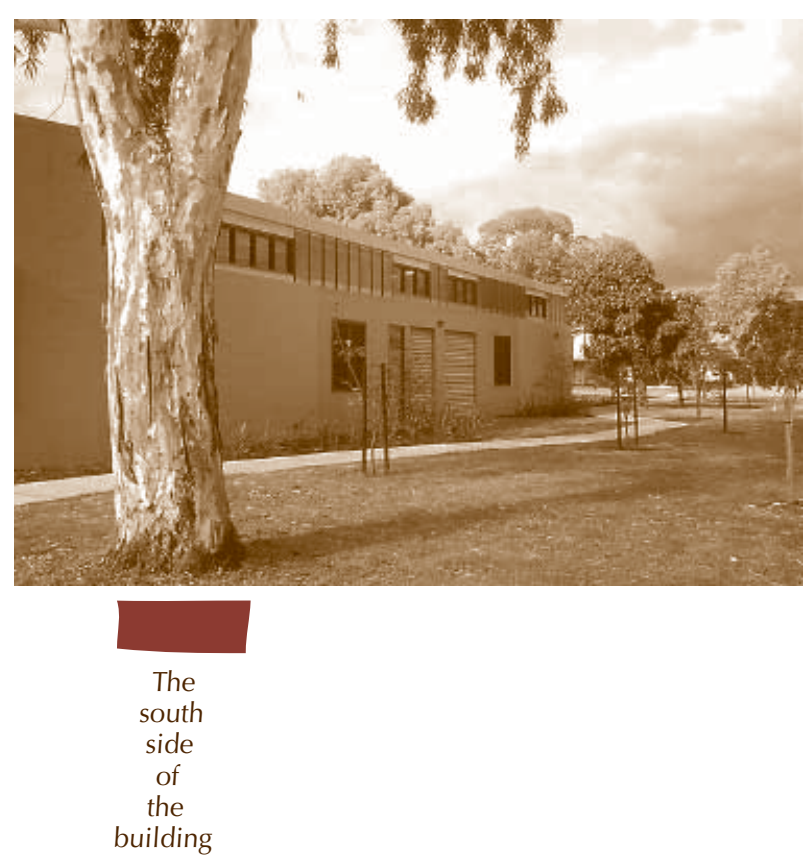

\section{Nooks and crannies}

The school has one central glazed corridor which adjoins the two external courtyards and passes through the internal courtyard. This allows for small alcoves along the corridor to protrude into the courtyards and the classroom areas, creating a range of north-facing sunny places for students and staff to meet - the intentional design of "nooks and crannies".

Conversely this circulation path also allows easy supervision of the entire school from a central point. This is an important feature as students are occasionally at risk of self harm or demonstrate aggressive behaviour toward others.

\section{Construction and costs}

Almost all of the original industrial building has been retained, with the steel structure and concrete block walls painted and left exposed within the rooms. However the deliberate use of "homely", non-institutional colours internally and externally has been effective in changing the perception of the industrial building.

The classrooms are naturally ventilated (supplemented by gas furnace heaters in winter) with high raking ceilings, ceiling fans, fixed louvres and banks of operable glass louvres allowing the evenings breezes to penetrate the building in summer so that it can cool down overnight.

New materials were selected on their recycled content with a general preference for natural materials over synthetic. Care was taken to specify low toxicity/zero emissions from paints and glues. 
The school is entirely accessible to staff or students with physical disabilities.

The building has a gross area of 702 square metres and construction took seven months at a total cost of AUD 780 000, which is AUD 1112 per square metre or AUD 26000 per student. Construction costs per student are particularly high by Australian standards; however this is a by-product of the specialist nature of the school, i.e. offering a full curriculum to just 30 students.

The areas where costs came under the most pressure were the budgets for garden landscaping and loose furniture which are seen as interim installations to be supplemented in the future.

The building has been in use for almost one year and has proven both to be spatially efficient and to promote interconnectedness between students and between staff and students.

It is hoped that a similar school offering facilities for boys who require like support will be built in Perth in the near future.

For further information, contact:

Eamon Broderick

Michael Broderick and Partners Architects

Fax: 61893813022

E-mail: eb_brodarch@iinet.net.au

\section{KOREA'S SCHOOL GROUNDS PROJECTS}

Korea has undertaken two projects to improve its school grounds: the Green School Project and the School Forest Pilot Project. The Korean Ministry of Education and Human Resources Development (MOE\&HRI) recently launched the Green School Project centred on existing urban schools with poor outdoor environments. The project encourages schools and local community members to work together to improve school settings, with the intention of cultivating students and creating a sound relationship between the educational and local communities. By developing wooded areas, ponds, grassy areas and places for growing study plants, the project aims to improve the learning environment and create environmentallyfriendly schools.
Once the project plan was finalized on 20 March 2003, directives were sent to the provincial offices of education. The plan provided for the provincial offices to designate pilot schools for the next two years (2004-5) and to provide incentives for participating school staff.

One hundred and one schools from a total of 417 applicants were selected following review by a committee in each region. The level of education was taken into consideration to include facilities from elementary, lower and upper secondary schools as well as schools for students with disabilities. Also considered was the type of project the schools planned to carry out, such as creating areas for learning about nature, ponds with their own ecosystems, parks for relaxation, gardens dedicated to study, and wooded and grassy areas.

The selected schools receive a two-year budget of KRW 50 million as well as technical advice. Recommendations for basic design and for purchasing and planting trees and shrubs are provided by the School Grounds Committee of Hak-Gyo-Sup Wi-won-hye (Forest of Life), a non-governmental organisation founded by a group of concerned citizens.

MOE\&HRI set aside KRW 2 billion for special local education financial subsidies for the first year of the Green School Project. In addition, the ministry has applied for KRW 5 billion from the general accounting budget for 2004 in order for the project to reach more schools.

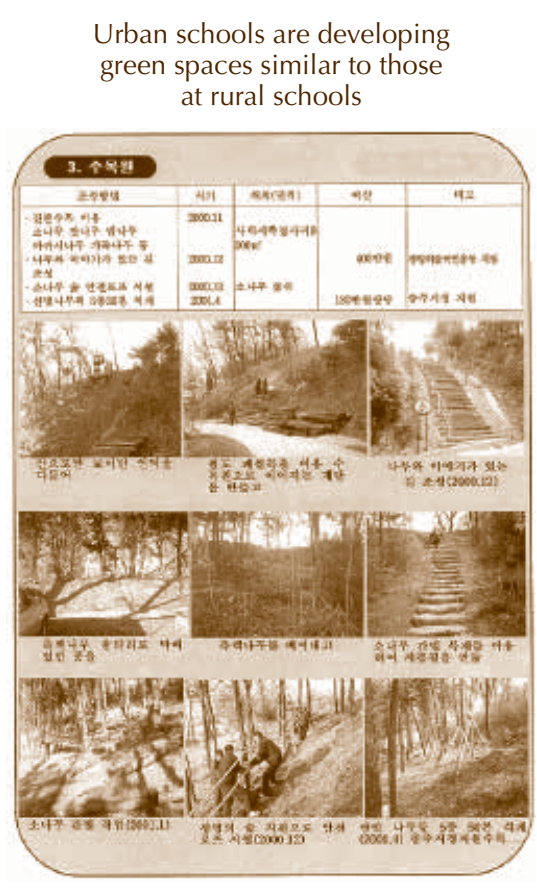

